\title{
Ecological impacts of human-induced animal behavior change
}

\author{
Margaret Wilson ${ }^{1}$, April Ridlon ${ }^{1}$, Kaitlyn Gaynor ${ }^{1}$, Steve Gaines ${ }^{1}$, Adrian Stier ${ }^{1}$, and \\ Benjamin Halpern ${ }^{1}$ \\ ${ }^{1}$ University of California Santa Barbara
}

June 2, 2020

\begin{abstract}
A growing body of literature has documented myriad effects of human activities on animal behavior, yet the ultimate ecological consequences of these behavioral shifts remain largely uninvestigated. While it is understood that, in the absence of humans, variation in animal behavior can have cascading effects on species interactions, community structure, and ecosystem function, we know little about whether the type or magnitude of human-induced behavioral shifts translate into meaningful ecological change. Here we synthesize empirical literature and theory to create a novel framework for examining the range of behaviorally mediated pathways through which human activities may affect different ecosystem functions. We highlight the few empirical studies that show the potential realization of some of these pathways, but also identify numerous factors that can dampen or prevent ultimate ecosystem consequences. Without a deeper understanding of these pathways, we risk wasting valuable resources on mitigating behavioral effects with little ecological relevance, or conversely mismanaging situations in which behavioral effects do drive ecosystem change. The framework presented here can be used to anticipate the nature and likelihood of ecological outcomes and prioritize management among widespread human-induced behavioral shifts, while also suggesting key priorities for future research linking humans, animal behavior, and ecology.
\end{abstract}

\section{Hosted file}

Wilson_manuscript.pdf available at https://authorea.com/users/328914/articles/456041ecological-impacts-of-human-induced-animal-behavior-change

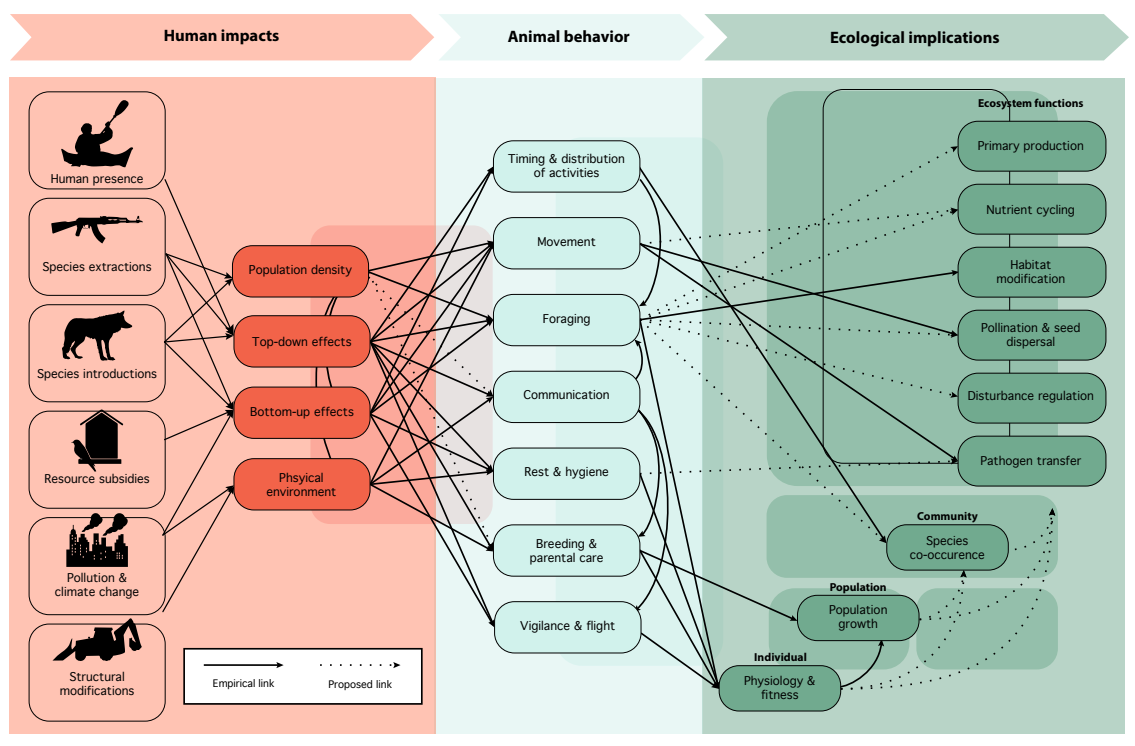



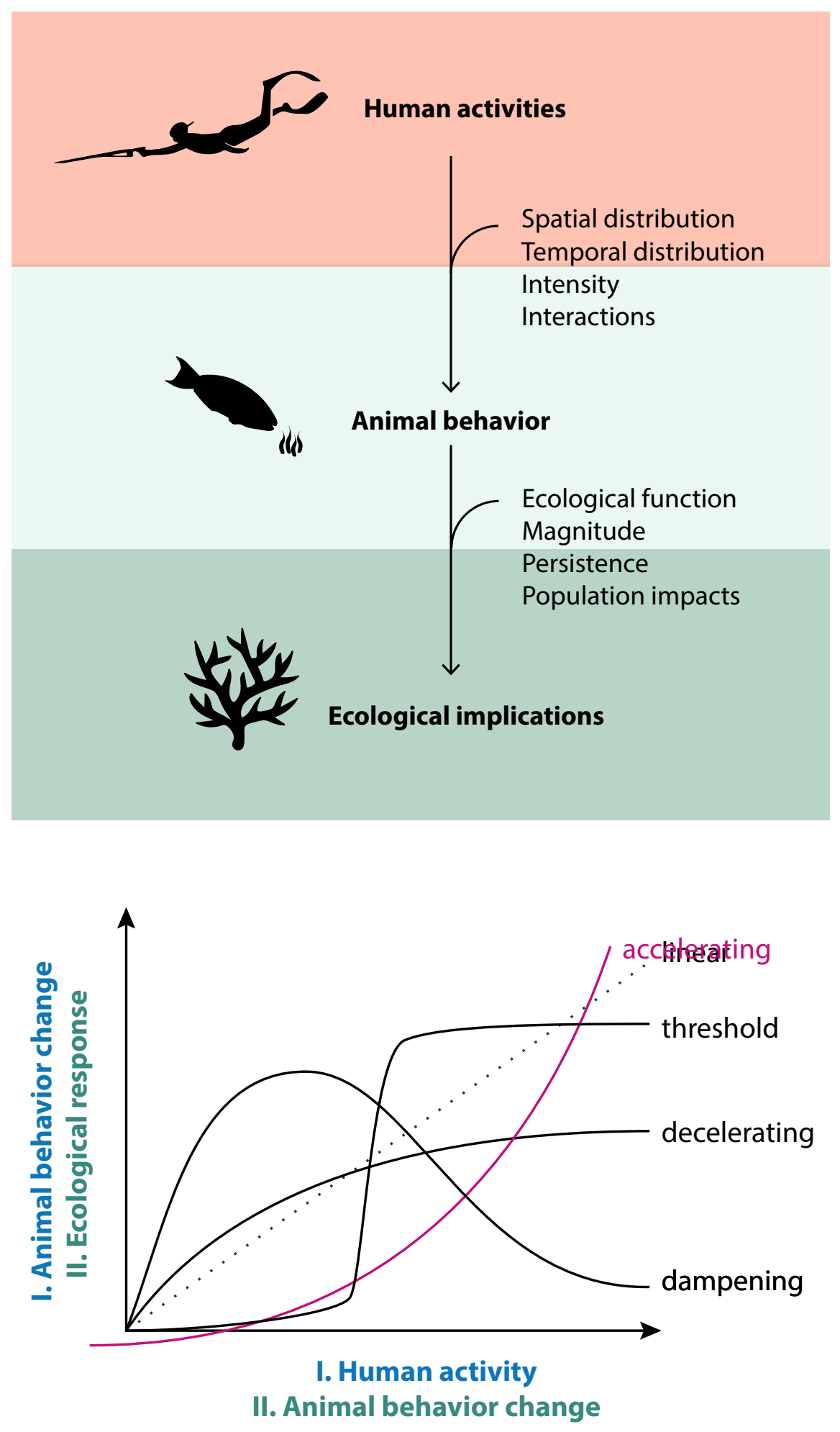